\title{
Facilitators and barriers to antiretroviral therapy adherence among adolescents in Ghana
}

\author{
This article was published in the following Dove Press journal: \\ Patient Preference and Adherence \\ 15 March 2016 \\ Number of times this article has been viewed
}

\author{
Daniel NA Ankrah ${ }^{1,2}$ \\ Ellen S Koster ${ }^{2}$ \\ Aukje K Mantel-Teeuwisse ${ }^{2}$ \\ Daniel K Arhinful ${ }^{3}$ \\ Irene A Agyepong ${ }^{4}$ \\ Margaret Lartey ${ }^{5,6}$ \\ 'Pharmacy Department, \\ Korle-Bu Teaching Hospital, \\ Accra, Ghana; ${ }^{2}$ Division of \\ Pharmacoepidemiology and Clinical \\ Pharmacology, Utrecht Institute \\ for Pharmaceutical Sciences (UIPS), \\ Utrecht, the Netherlands; ${ }^{3}$ Noguchi \\ Memorial Institute for Medical \\ Research, University of Ghana \\ (Legon), ${ }^{4}$ Health Policy, Planning and \\ Management, University of Ghana \\ School of Public Health, ${ }^{5}$ Department \\ of Medicine, University of Ghana \\ Medical School, ${ }^{6}$ Department of \\ Medicine and Therapeutics, Korle-Bu \\ Teaching Hospital, Accra, Ghana
}

Introduction: Adherence to antiretroviral therapy (ART) is known to be challenging among adolescents living with HIV/AIDS, notwithstanding the life-saving importance of this therapy. Of the global total number of adolescents living with HIV in 2013, 83\% reside in sub-Saharan Africa. The study aimed to identify facilitators of and barriers to antiretroviral treatment adherence among adolescents in Ghana.

Methods: A cross-sectional qualitative study using semi-structured interviews for data collection was carried out among adolescents (aged 12-19 years) at the adolescents HIV clinic at the Korle-Bu Teaching Hospital in Ghana. Predominantly open-ended questions relating to ART were used. Interviews were done until saturation. In total, 19 interviews were conducted. Analysis was done manually to maintain proximity with the text.

Findings: The main facilitators were support from health care providers, parental support, patient's knowledge of disease and self-motivation, patient's perceived positive outcomes, and dispensed formulation. The identified barriers were patient's forgetfulness to take medicines, perceived stigmatization due to disclosure, financial barriers, and adverse effects of ART. Support from health care workers was the most frequently mentioned facilitator, and patient's forgetfulness and perceived stigmatization after disclosure were the most frequently mentioned barriers. Self-motivation (knowledge induced) to adhere to treatment was a specific facilitator among older adolescents.

Conclusion: Continuous information provision in addition to unflinching support from health care workers and parents or guardians may improve adherence among adolescents. Also, interventions to reduce patient forgetfulness may be beneficial. A multi-sectorial approach would be needed to address adolescent disclosure of HIV/AIDS status.

Keywords: qualitative study, forgetfulness, disclosure, parental support, stigmatization

\section{Introduction}

As of 2013, of the total number of adolescents (people aged between 10 and 19 years ${ }^{1}$ ) living with HIV, 83\% resided in sub-Saharan Africa (SSA). ${ }^{2}$ Furthermore, between 2001 and 2013, while trends in global AIDS-related deaths decreased among other age groups, it increased among those aged 10-19 years. ${ }^{2}$ Factors responsible for these observations may include a lack of knowledge of HIV, inequalities in the availability of health services, growing up without parents, early sexual activity and a generally risky behavior, ${ }^{3}$ and non-adherence to antiretroviral therapy (ART).

The advent of ART has been a major respite for people infected with HIV, but optimal adherence is needed for best outcomes. Non-adherence to ART adversely affects clinical, ${ }^{4,5}$ immunological, and virological outcomes of patients.

In general, adherence among adolescents to chronic medication has been found to be lower compared with younger children or adults ${ }^{6,7}$ due mainly to the transition
Correspondence: Daniel NA Ankrah Pharmacy Department, Korle-Bu Teaching Hospital, PO Box 77, Korle-Bu, Accra, Ghana

Tel +233302636168

Fax +233302673729

Email d.ankrah@uu.nl
Patient Preference and Adherence 2016:10 329-337

Dovepress

http://dx.doi.org/10.2147/PPA.S96691
329

(c) (1) (8) 2016 Ankrah et al. This work is published and licensed by Dove Medical Press Limited. The full terms of this license are available at https://www.dovepress.com/terms.php (c) ${ }_{\mathrm{BY}}$ NC and incorporate the Creative Commons Attribution - Non Commercial (unported, v3.0) License (http://creativecommons.org/licenses/by-nc/3.0/). By accessing the work you hereby accept the Terms. Non-commercial uses of the work are permitted without any further permission from Dove Medical Press Limited, provided the work is properly attributed. For permission for commercial use of this work, please see paragraphs 4.2 and 5 of our Terms (https://www.dovepress.com/terms.php). 
process of this subgroup. ${ }^{8}$ This transition is a stage in life characterized by significant biological, physical, and psychosocial changes marking the beginning of adulthood. At this stage, adolescents experience changes affecting self-control. Adherence-enhancing interventions in this group have had poorly sustained outcomes so far. ${ }^{9}$ In addition, demographic factors like increasing age and female sex have been found to be associated with non-adherence among adolescents. ${ }^{10,11}$

Adherence levels are suboptimal, averaging up to $50 \%$ of the infected youth. ${ }^{12,13}$ Among young people living with HIV/AIDS, numerous behavioral challenges, such as peer pressure and concerns about body image, have been identified as being associated with adherence behavior. ${ }^{14}$ Furthermore, psychological factors, threats to health status disclosure, and interpersonal relations ${ }^{15-17}$ have also been linked to adherence to treatment. Also, stigma and discrimination by friends, ${ }^{18}$ a complex ART regime, ${ }^{19}$ and an adverse drug effect ${ }^{20}$ have all been found to be associated with a decline in adherence.

According to Radcliffe et al, ${ }^{21}$ regular follow-up of treatment improves adherence among young people. Adolescents who believed that quality of life was improved with medication were more likely to adhere to treatment. ${ }^{22}$ In a systematic review, patient and caregiver education, self-monitoring, telephone follow-up, and self-support ${ }^{23}$ have been mentioned as key strategies to improve adherence among the youth. A schematic framework of adolescent adherence is shown in Supplementary materials (Figure S1).

Very few studies in SSA have targeted adherence among adolescents to ARTs, resulting in an unmet need among this group. It is important to assess the perspective from adolescents themselves in what they see as main treatment barriers and facilitators helping them to achieve better treatment adherence. Using semi-structured interviews, this study intends to explore barriers and facilitators to antiretroviral (ARV) adherence among HIV-infected adolescents on treatment in Ghana, a low- and medium-income country in SSA.

\section{Methodology Study setting and population}

The study was conducted at the Fevers Unit of the Department of Medicine and Therapeutics of the Korle-Bu Teaching Hospital in Ghana. The Fevers Unit is a referral center responsible for the registration and management of all cases of HIV in adults and adolescents older than 12 years. There are three outpatient clinic days per week, each with an average attendance of $\sim 120$ patients. In addition, there is a special clinic for HIV-infected adolescents on Thursdays.
A qualitative cross-sectional study involving adolescents aged between 12 and 19 years attending the adolescents HIV clinic was performed. The decision to choose 12 years as the lower limit instead of 10 years was because the adolescent clinic is attended by children aged $\geq 12$ years. Adolescents, both school-going and nonschool-going, who had been on treatment for a minimum of 6 months at the study site were eligible for participation. There were no proxy interviews. Adolescents at the pharmacy waiting to refill ARV prescriptions were approached, and a request to participate in a study was made. Those who agreed signed a written informed consent. During selection, an attempt was made to have a representative number of people in age groups $12-15$ and 16-19. This was to ensure that the views of both younger and older adolescents were captured.

\section{Ethics statement}

Ethical approval was obtained from the Ethical and Protocol Review Committee of the University of Ghana Medical School, Accra, Ghana.

\section{Data collection}

Semi-structured interviews were administered to all participants using predominantly open-ended interview guide until data saturation was reached. There were follow-on questions depending on an interviewee's response to a previous question. Also, there were questions inviting participants to narrate a scenario, for example, "tell me about how you started taking these antiretroviral medicines". All interviews were audio-recorded with the permission of interviewees. Interviews were held in a secured cabinet (an office) at the pharmacy department. Interviews were in English or a local language preferred by the interviewee. Themes explored were on general medication use, adherence to treatment, influence of others, and social activities (Figure S2). Interviews were conducted until no new information emerged from the process (saturation). The interviews were conducted over a period of 6 weeks and were all done by the lead author. Each interview lasted between 20 and 40 minutes.

\section{Data handling and analysis}

Recorded interviews in English were transcribed verbatim. Interviews in the local language were translated and transcribed into English with back-translation checks. Data were coded by two researchers (the lead author and a social scientist with experience in qualitative research). Where discrepancies occurred, the two coders met, discussed, and 
came to an agreement. All interviews were anonymized during this process.

\section{Analysis}

Analysis was done manually. Those who started ARTs from childhood as well as those who started later in life were identified. This gave an idea of those infected through vertical transmission and those from other forms of infection. Data analysis was done using framework analysis. ${ }^{24,25}$ The scripts were read again and again (between four and six times) to identify all key ideas and recurrent themes. With the aims and objectives of the study in focus, the data were indexed and labeled for further exploration. Emerging ideas were coded and assigned to various themes. A chart of the main themes and responses from corresponding interviewees was constructed. Information from the chart was continuously matched with coded information until all important facts providing explanation for the findings were identified. These facts were then structured as barriers and facilitators of adherence to ART.

\section{Findings \\ Sociodemographic characteristics}

A total of 20 adolescents were approached for participation, but one declined because he was late for school. The mean age of interviewees was 16.3 years with a standard deviation of 1.9 years. The youngest person was 14 years, and the oldest was 19 years. There were three boys and five girls in the 12- to 15-year age group, and there were four boys and seven girls in the older age group. Among those interviewed, two had completed senior high school, four were in senior high school, 12 were in junior high school, and one dropped out of school at class 5. Of the 19 interviews, 17 were in English, and two in a local language.

Only three of those interviewed knew the names of at least one of their ARV medicines, but most of them knew the name of the most used medicine for opportunistic infections (cotrimoxazole). Two patients (a boy and a girl) reported that their situation was not a result of vertical transmission. The boy, a 14-year old, said he had the infection through the use of an infected needle, and the other, a 19-year-old girl, said she was infected by her former boyfriend.

There were unique themes that were classified as facilitators or barriers, but occasionally, there were specific ones that apart from encouraging adherence in some participants made others default. A typical case was positive outcomes from ARV treatment where one patient reported that it made him think that he was cured. The findings have been grouped under "facilitators" and "barriers" with the identified themes serving as subsections.

\section{Facilitators}

\section{Support from health care providers}

All those interviewed said that the contribution from clinical staff (doctors, nurses, laboratory technicians, registry staff) as well as pharmacy staff has helped them to be more conscientious in taking their medications. Consequently, this was the most frequently mentioned facilitator. This was how a 16-year-old female reported it:

The influence of the health workers has helped me a lot with my medicines. What they tell me at the clinic and at the adherence counselling unit encourages me to take my medicines regularly.

Some patients compared the care they had from other health workers with what is given them at the treatment site. This was what one such patient (female, 17 years) said:

It has helped me. If I were not being treated well I would stop coming here. I might even stop taking my medicine and this would surely affect my health. Unlike the doctors who treated me before..., those at the treatment centre are nice to me and they help me to take my medicine well.

\section{Parental support}

Although not all respondents said they were actively assisted by their parents, those who did were happy with such support because it improved their medication-taking habits. One respondent (female, 16 years) captured it as follows:

At home my parents remind me to take my medicines. When I am taking it on my own I first show it to them. My parents have been supportive and this has helped a lot with the way I take my medicines.

\section{Patient's knowledge of disease and self-motivation}

Knowledge of the nature of HIV and knowing that HIV is only controlled by taking your medicines facilitated the desire of some patients to remember to take their medicines. Almost all patients interviewed $(n=16)$ mentioned that HIV is a killer disease found in the blood. Some mentioned that being serious with your medication could avert such deaths. A 15-year-old girl expressed knowledge of the disease as follows:

It is a bad sickness that kills a lot. It is not good. When you take your medicines seriously you will not die but if you 
stop, you will die. It can be found in the blood. It is also in breast milk. If you use a blade and the same towel or sponge with an HIV infected person you can get HIV. If you have unprotected sex with someone who has the virus you can get the virus.

Self-motivation through acquired knowledge, though not the general view, was mentioned by older respondents as a motivator for taking medicines. An 18-year-old post-senior high school girl gave this account:

First of all I was counselled on the benefits. Personally I read a lot about the medicines and learn a lot that way. At the moment I have assured myself that I am going to be on this medicine for the rest of my life and I do not think anything will hinder me.

\section{Patient's perceived positive outcomes}

Participants mentioned the physical changes they experience while on medication as a driver for adherence. One female patient (14 years old) was all praises for what the medicines had done for her,

I think it is ok. At the moment I have gotten used to the medicines. I think it is very necessary; it is the reason I am alive today. It helps to boost my immune system and prevents further diseases from occurring. I believe it is by the grace of God that these medicines were made.

\section{Dispensed formulation}

Some participants $(n=5)$ in the study mentioned that tablets were more convenient compared with syrups. Because of their daily activities and the treatment times, adolescents needed to carry their medication from one place to the other. An 18-year-old male said this about the tablets he takes now compared with the syrup he was previously using:

My medicines have been changed before. I used to take syrup but when I moved to the Fevers Unit it was changed to tablets. I prefer the tablets to the syrup because it is more convenient to carry around.

\section{Barriers}

A number of reasons were mentioned as responsible for patients' inability to continue treatment as scheduled.

\section{Patient's forgetfulness to take medicines}

All respondents mentioned forgetfulness due to preoccupation with other life events as reason for non-adherence. These included activities such as attending church service, early start of school activities, socializing, and helping parents/guardians with petty trading activities. For example, a boy of 14 indicated that he sometimes forgets to take his medicines because he goes out socializing with his peers:

I take my medicine because I do not want to get ill like before. I want to feel healthy. I sometimes forget to take my medicines in the evening because I go out with my friends ...

Sometimes I do not come home early enough.

\section{Perceived stigmatization due to disclosure}

Fear of stigmatization by their mates in school and their friends or peers at home was mentioned by all those interviewed. While some interviewees would not even let their mates know that they are taking ARV medicines, others admitted that their mates were aware but were not sure of what disease the drugs were for. Reasons like asthma and sickle cell anemia were mentioned as some of the answers given when colleagues asked for the purpose of their medicines. One female respondent, 16 years old, explained the situation in this form:
At school I take my medicines normally. My friends see me and sometimes ask why I always take medicines. I just tell them it is because I have sickle cell anaemia, ... if I tell them it is for HIV they will laugh at me. I will be ashamed and may not take my medicine. If I do not take my medicine I will die so I do not think it is right for me to tell them.

\section{Financial barriers}

Although ARVs are free, not all patients find it easy to pay the additional cost of frequent travels for their medication due to financial constraints on their parents/guardians. Such patients sometimes run out of ARVs and default in medication routine. A 15-year-old girl living with her mother $\sim 8 \mathrm{~km}$ from the treatment center explained:

I normally come to the clinic with my mum but today I decided to come all by myself. I sometimes have a problem with transportation. Even today, my mum had to borrow money from a friend for my transportation to this place. She was complaining that she had not yet received her salary.

\section{Adverse effects of ART}

Adverse drug reactions associated with some of the medications, particularly dizziness, was mentioned as one of the most worrying attributes that discouraged them from taking their medicines. This was how one 16-year-old boy put it: 
Whenever I take the medicine I feel dizzy, I came to report and it was changed. I would have stopped taking it. If the side effects are severe I cannot take it.

Although most patients complained about the number of medicines taken, they did not consider it as a direct cause for non-adherence. A 17-year-old boy explained it this way:

I take haematinics and cotrimoxazole in addition to my medicines. I feel the medicines are a lot. However, it does not affect the way I take them. In the morning I take the two medicines and the antiretroviral dose and I take only the antiretroviral in the evening.

\section{Discussion}

This was a qualitative study in which 19 adolescents were interviewed to identify facilitators and barriers to ARV adherence among adolescents in Ghana. To our knowledge, no study in Ghana has addressed ART adherence in this specific age group before. Adolescents mentioned a variety of factors beneficial or detrimental to ART adherence. Support from health care providers at the treatment site, parental support, patient's knowledge of disease and self-motivation, patient's perceived positive outcomes, and dispensed treatment formulation were the facilitators mentioned. The barriers mentioned were patient's forgetfulness to take medicines, perceived stigmatization due to disclosure, financial barriers, and adverse effects of ART. The most frequently mentioned facilitators were support from health care workers at the treatment site and parental care. Forgetfulness and perceived stigmatization postdisclosure were identified as the most recurrent barriers to ART adherence.

Forgetfulness has been reported as a barrier to adherence among adolescent patients in previous research. ${ }^{26}$ In a systematic review of qualitative studies on adherence to ART, ${ }^{27}$ forgetfulness was identified as a major contributor to non-adherence. Forgetfulness has also been reported as a major factor of non-compliance to medicines and clinic visits. ${ }^{28-30}$ Social activities according to this study had a strong effect on patients' ability to remember their treatment times. To overcome this, the use of reminders may be considered. The use of short message service among the youth has been found to improve self-reported adherence, ${ }^{31}$ and Puccio et $\mathrm{al}^{32}$ have reported the benefits of cell phone use among adolescents and young adults. Most adolescents in Ghana at the moment own mobile phones which come with reminder alarms. Caregivers can take advantage of this and advise adolescents appropriately.
A factor that almost all interviewees reported as adversely affecting the way they take their medicine was perceived stigmatization as a result of disclosure to their friends and school mates. According to some children, their parents or guardians advised them not to discuss their sero-status or ARV medication with their peers. While parents and guardians want good health for their children, sometimes they may be overprotective. Parents need to encourage their wards to disclose their HIV status to their close friends, but this would demand a lot of education on the part of the public on how to handle such information for it not to be counterproductive. This is because of its profound effect on stigmatization and discrimination which has been found to be associated with adherence. ${ }^{18}$ Perceived stigmatization and discrimination of HIV/AIDS patients (including those on treatment) cut across every facet of Ghanaian society, and this will take a holistic approach to circumvent. Parents and guardians, the health sector, the educational sector, and HIV/AIDS advocacy groups should come together to discuss this agendum. Mburu et al have suggested a public health intervention to help adolescent patients and their parents or guardians. ${ }^{33}$ Peer support ${ }^{34}$ has been mentioned as a major facilitator of adherence among adolescents with a chronic disease, but this needs a lot of education on disease etiology among all those in this age group. The International Association of Providers of AIDS Care in conjunction with the World Health Organization and the Pan American Health Organization have just developed an appropriate training manual $^{35}$ for peer education of HIV-positive adolescents and young adults. This may be helpful in improving the emotional and physical lives of adolescents. Additionally, counseling for infected adolescents at the HIV clinic should include the importance of protecting uninfected peers from being infected.

Adverse drug effects also deterred adherence, and most patients mentioned periodic dizziness as the cause. This calls for proper monitoring and early intervention to prevent non-adherence to treatment. Health workers should educate people living with HIV/AIDS, especially adolescents, on treatment-associated side effects before treatment initiation and during treatment. Information should be targeted toward activities that will minimize side effects.

Respondents were unanimous about the benefits received from health care workers and its effect on medication administration. To improve or at least maintain such standards, lessons can be learned from the adolescents training curriculum developed by the Zambian Ministry of Health in collaboration with International Center for AIDS Care and Treatment 
Programs. ${ }^{36}$ This is a youth-friendly HIV care manual for adolescents living with HIV and their caregivers.

Support from parents (both financial and social) was highly rated by interviewees. Studying adherence in general, practical support from parents for adolescents has been mentioned by Taddeo et $\mathrm{al}^{37}$ as positive. They suggested the reinforcement of family closeness, cohesiveness, and problem-solving skills with adolescents.

Adolescents cannot always take their medicines at home because they may be involved with public activities that may overlap with their treatment times. They may want to keep their ARV medicines away from their peers. For such patients, tablets, rather than syrups, will be more convenient. On limited occasions, liquid preparations have been dispensed to adult HIV patients in Ghana because there were shortages with tablets and treatment could not be broken. Care must be taken to eliminate such situations.

Contrary to reports, ${ }^{19}$ a complex ART regimen was not problematic in this study. Claxton et $\mathrm{al}^{38}$ have explained that treatment complexity is not the main issue, but the relationship between a patient's routine, expectations, and preferences is crucial. Most respondents explained that taking the drugs was not very challenging because of the 12-hourly dose regimens.

\section{Limitations of the study}

Using a qualitative study provided opportunity to explore the issues of interests in depth in a way that would not be possible with quantitative studies. Although this may affect generalizability, qualitative studies tend to provide information as to what to investigate in a more statistically generalizable study. The research involved patients' own account of events which may be subjective. However, the degree of consistency in response is assuring, and a source of credibility to the study. This study did not assess the relationship between facilitators and barriers, and direct measurement of adherence.

\section{Conclusion}

The most recurrent barriers to ART adherence were forgetfulness and perceived stigmatization post-disclosure by patients. Adolescents were unwilling to reveal information on their HIV disease status to their peers; they mentioned other morbidities as responsible for their current situation. This observation needs to be addressed by all stakeholders of HIV/AIDS in order to move adolescent HIV treatment forward. The most frequently mentioned facilitators to ART adherence among adolescents in this study were the role of health care workers at the treatment site and parental support. The findings provide ideas as to interventions that can improve adherence among this subgroup, and provide the information to design, implement, and evaluate their impact with a more statistically generalizable design.

\section{Acknowledgments}

The authors' sincerest appreciation goes to Madam Elaine Awumee, Miss Mary Nordor, Miss Sabina Ansah, and all adherence counselors at the Korle-Bu Teaching Hospital for their invaluable assistance during patient selection and data collection for this study. The authors thank Rev Dr Albert Martins (the second coder) for finding time to assist.

\section{Disclosure}

The authors report no conflicts of interest in this work.

\section{References}

1. Adolescents: health risks and solutions. Fact sheet $N^{\circ} 345$ [webpage on the Internet]. World Health Organization. Available from: http:// www.who.int/mediacentre/factsheets/fs345/en/. Accessed February 3, 2016.

2. ALL IN \#EndAdolescentAIDS; 2015. Available from: www.unicef.org/ media/files/ALL_IN_brochure_En_v02(1).pdf. Accessed July 26, 2015.

3. Ross D, Dick B, Ferguson J, editors. Preventing HIV/AIDS in Young People: A Systematic Review of the Evidence from Developing Countries: UNAIDS Interagency Task Team on HIV and Young People. Geneva: WHO Press; 2006.

4. Timmreck TC, Randolph JF. Smoking cessation: clinical steps to improve compliance. Geriatrics. 1993;48:63-66.

5. Farmae KC. Methods for measuring and monitoring medication regimen adherence in clinical trials and clinical practice. Clin Ther. 1999; 21:1074-1090.

6. Wamboldt F, Bender B, Wamboldt M, et al. Psychosocial correlates of pediatric MDI adherence. Am J Respir Care Med. 2000;161(13):A711.

7. Wamboldt F, Bender B, Ho J, et al. Correlates of MDI adherence: a replication study. Am J Respir Care Med. 2002;165(8):A197.

8. Pai AL, Ostendorf HM. Treatment adherence in adolescents and young adults affected by chronic illness during the health care transition from pediatric to adult health care: a literature review. Child Health Care. 2011;40:16-33.

9. Bender B, Milgrom H, Apter A. Adherence intervention research: what have we learned and what do we do next? J Allergy Clin Immunol. 2003;112(3):489-494.

10. Williams PL, Storm D, Montepiedra G, et al. Predictors of adherence to antiretroviral medications in children and adolescents with HIV infection. Pediatrics. 2006;118:e1745-e1757.

11. Chandwani S, Abramowitz S, Koenig LJ, Barnes W, D’Angelo A. A multimodal behavioral intervention to impact adherence and risk behavior among perinatally and behaviorally HIV infected youth: description, delivery, and receptivity of adolescent impact. AIDS Educ Prev. 2011;23:222-235.

12. Murphy DA, Belzer M, Durako SJ, Sarr M, Wilson CM, Muenz LR. Longitudinal antiretroviral adherence among adolescents infected with human immunodeficiency virus. Arch Pediatr Adolesc Med. 2005;159: 764-770.

13. Becker SL, Dezii CM, Burtcel B, Kawabata H, Hodder S. Young HIV-infected adults are at greater risk for medication nonadherence. MedGenMed. 2002;4(3):21.

14. More positive living. Strengthening the health sector response to young people living with HIV. Available from: http://www.who. int/maternal_child_adolescent/documents/pdfs/more_positive_ living_2008.pdf. Accessed February 18, 2016. 
15. Murphy DA, Wilson CM, Durako SJ, et al. Antiretroviral medication adherence among the REACH HIV-infected adolescent cohort in the USA. AIDS Care. 2001;13:27-40.

16. Hosek S, Harper G, Domanico R. Psychological and social difficulties of adolescents living with HIV: a qualitative analysis. J Sex Educ Ther. 2000;25:269-276.

17. Murphy DA, Moscicki AB, Vermund SH, Muenz LR. Psychological distress among HIV(+)adolescents in the REACH study: effects of life stress, social support, and coping. The Adolescent Medicine HIV/AIDS Research Network. J Adolesc Health. 2000;27:391-398.

18. Rao D, Kekwaletswe TC, Hosek S, Martinez J, Rodriguez F. Stigma and social barriers to medication adherence with urban youth living with HIV. AIDS Care. 2007;19:28-33.

19. Parienti JJ, Bangsberg DR, Verdon R, Gardner EM. Better adherence with once-daily antiretroviral regimens: a meta-analysis. Clin Infect Dis. 2009;48(4):484-488.

20. Murphy DA, Sarr M, Durako SJ, Moscicki AB, Wilson CM, Muenz LR. Barriers to HAART adherence among human immunodeficiency virusinfected adolescents. Arch Pediatr Adolesc Med. 2003;157:249-255.

21. Radcliffe J, Tanney M, Rudy B. Post-traumatic stress and adherence to medical treatment among youth with HIV. J Adolesc Health. 2006;38:110-111.

22. Belzer ME, Fuchs DN, Luftman GS, Tucker DJ. Antiretroviral adherence issues among HIV positive adolescents and young adults. $J$ Adolesc Health. 1999;25:316-319.

23. Reisner SL, Mimiaga MJ, Skeer M, et al. A review of HIV antiretroviral adherence and intervention studies among HIV-infected youth. Top HIV Med. 2009;17(1):14-25.

24. Green J, Thorogood N. Qualitative Methods for Health Research. 2nd ed. London: Sage Publications; 2009.

25. Pope C, Ziebland S, Mays N. Qualitative research in health careanalysing qualitative data. BMJ. 2000;320:114-116.

26. Murphy DVA. Barriers to haart adherence among immunodeficiency vírus-infected adolescents. Arch Pediatr Adolesc Med. 2003;157: 249-255.

27. Vervoort SCJM, Borleffs JCC, Andy IM, Hoepelman AIM, Grypdonck MHF. Adherence in antiretroviral therapy: a review of qualitative studies. AIDS. 2007;27:271-281.
28. Hernandez-Ronquillo L, Tellez-Zenteno JF, Garduno-Espinosa J, Gonzalez-Acevez E. Factors associated with therapy noncompliance in type-2 diabetes patients. Salud Publica Mex. 2003;45:191-197.

29. Ponnusankar S, Surulivelrajan M, Anandamoorthy N, Suresh B. Assessment of impact of medication counseling on patients' medication knowledge and compliance in an outpatient clinic in South India. Patient Educ Couns. 2004;54:55-60.

30. Wai CT, Wong ML, Ng S, et al. Utility of the Health Belief Model in predicting compliance of screening in patients with chronic hepatitis B. Aliment Pharmacol Ther. 2005;21:1255-1262.

31. Dowshen N, Kuhns LM, Johnson A, et al. Improving adherence to antiretroviral therapy for youth living with HIV/AIDS: a pilot study using personalized, interactive, daily text message reminders. $J$ Med Internet Res. 2012;14(2):e51.

32. Puccio JA, Belzer M, Olson J, et al. The use of cell phone reminder call for assisting HIV-infected adolescents and young adults adhere to highly active antiretroviral therapy: a pilot study. AIDS Patient Care STDS. 2006;20(6):438-444.

33. Mburu G, Hodgson I, Kalibala S, et al. Adolescent HIV disclosure in Zambia: barriers, facilitators and outcomes. J Int AIDS Soc. 2014 $17: 18866$

34. Miller-Johnson S, Emery RE, Marvin SR, Clarke W, Lovinger R, Martin M. Parent-child relationships and management of insulindependent diabetes mellitus. J Consult Clin Psychol. 1994;62:603-610.

35. International Association of Providers of AIDS Care. Peer Education Trainer's Manual - Increasing the Knowledge and Skills of HIV-Positive Adolescents and Young Adults to Live Emotionally, Physically, and Sexually Healthy Lives. Washington, DC: IAPAC; 2014. Available from: http://www.iapac.org/uploads/IAPAC-PAHO_HIV+_Youth_ Peer_Ed_Manual_123114.pdf. Accessed June 26, 2015.

36. Adolescent HIV care and treatment. Available from: http://files. icap.columbia.edu/files/uploads/1423_ZM_Participant_Manual.pdf. Accessed January 20, 2015.

37. Taddeo D, Egedy M, Frappier J. Adherence to treatment in adolescence. Paediatr Child Health. 2008;13(1):19-24.

38. Claxton AJ, Cramer J, Pierce C. A systematic review of the associations between dose regimens and medication compliance. Clin Ther. 2001; 23(8):1296-1310. 


\section{Supplementary materials}

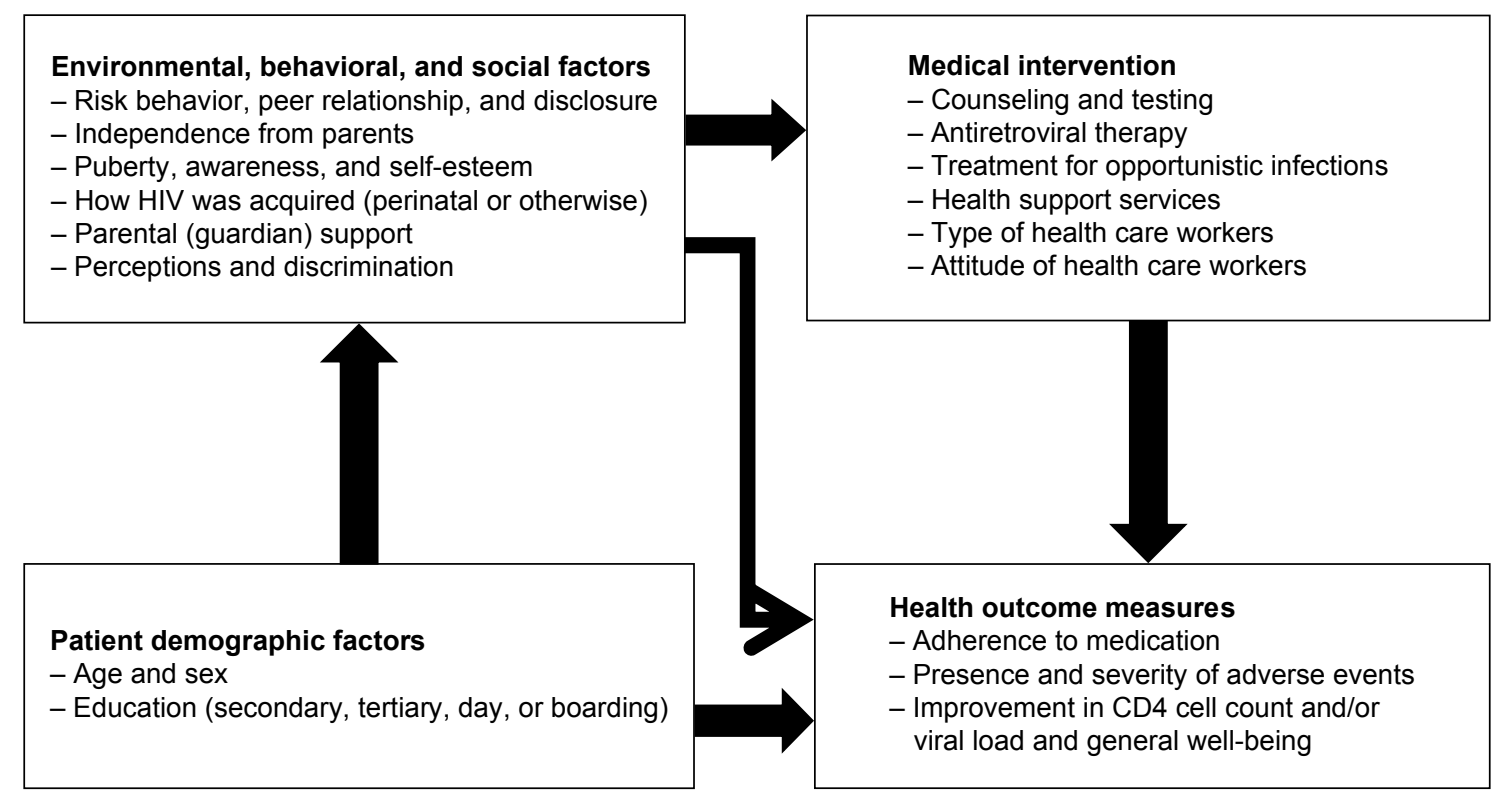

Figure SI Conceptual framework for adherence to ART among adolescents.

Abbreviation: ART, antiretroviral therapy.

\section{Knowledge of HIV}

Q. Please tell me what you know about the HIV/AIDS disease.

Q. Please tell me about how you got infected with the disease.

\section{General medication use}

Q. How many antiretroviral therapies (ARTs) are you taking at the moment?

Q. What is/are the name(s) of your medicine(s)?

Q. Tell me something about when you started taking these medicines.

Q. Do you have other medicines in addition to these? How do you feel about the number of medicines you are taking so far?

Q. How did you feel during the first 2 weeks after starting your medication?

Q. Have you ever had a change of medication? What was the reason for this change?

Q. What is your own perception of these medicines? (Do you think they are necessary?)

Adherence - medication intake behavior

Q. How often do you take your medicine?

Q. Please tell me what makes you take your medicines well.

Q. Please tell me what does not make you take your medicines well.

Q. Please tell me on which day(s) of the week you are most likely to forget to take your medicines.

Q. Why in your opinion is this so?

Q. Please tell me about your experiences at home when taking your medicines.

Q. Please tell me about your experiences at school when taking your medicines.

Q. Please describe your worst experience concerning your medicines.

Figure S2 (Continued) 


\section{Influence of others}

Q. What is your relationship with the health workers at the clinic?

Q. What is your relationship with those who serve you medicines?

Q. How has these influenced your attitude toward your medicines?

Q. In your opinion, how has living with (or without) your parents affected the administration of your ARTs?

Q. Do you often discuss your condition (HIV status) with your peers?

Q. If no, is there any reason(s) why?

Q. If yes, how has that affected your drive to continue taking your ARTs?

\section{Alcohol/drug use}

Q. Do you drink alcohol or smoke? Do you use other drugs like crack or cocaine?

Q. If yes, do you get hangover from such practice? How does this affect your routine uptake of ARTs?

\section{Conclusion}

Q. What else would you like to tell me about your medicines that we have not discussed today?

Figure S2 Nature of questions asked (English).

\section{Publish your work in this journal}

Patient Preference and Adherence is an international, peer-reviewed, open access journal that focuses on the growing importance of patient preference and adherence throughout the therapeutic continuum. Patient satisfaction, acceptability, quality of life, compliance, persistence and their role in developing new therapeutic modalities and compounds to optimize clinical outcomes for existing disease states are major areas of interest for the journal. This journal has been accepted for indexing on PubMed Central. The manuscript management system is completely online and includes a very quick and fair peer-review system, which is all easy to use. Visit http://www. dovepress.com/testimonials.php to read real quotes from published authors.

\footnotetext{
Submit your manuscript here: http://www.dovepress.com/patient-preference-and-adherence-journal
} 